\title{
MEDIAÇÃo INTERCULTURAL COM ÁLBUNS ILUSTRADOS
}

\author{
Margarida Morgado
}

\begin{abstract}
RESUMo
É grande o potencial de utilização de livros-álbum no contexto da mediação intercultural com crianças e jovens, que recorrem à multimodalidade para contar histórias sobre condições sociais de vida mundo atual. Quando criteriosamente selecionados, os livros-álbum permitem aos jovens encontrar representações diversas de multiculturalidade e de atuação intercultural significativas. Apresentam-se alguns exemplos de como um conjunto de livros-álbum da coleção do projeto IDPBC (Identity and Diversity in Picture Book Collections) pode ser usado para explorar tópicos de superdiversidade das sociedades modernas, tais como, viver em comunidades culturalmente muito diversas, construção de múltiplas identidades linguísticas, mobilidades humanas (forçadas e voluntárias) e migrações, em massa. Estes recursos ficcionais, que se apresentam como geradores de empatia entre os leitores, podem ser usados para ajudar crianças a compreender a diversidade crescente em que vivem, bem como os fenómenos contemporâneos de migração ou refugiados. Eles podem também contribuir para ajudar os jovens a compreender a complexidade social à escala global e ao nível dos direitos humanos e da convivência na diversidade de uma cidadania global. Sugerem-se por fim abordagens didáticas inclusivas destes materiais, passíveis de serem usadas com crianças (com idades dos cinco aos 12 anos) em situações de acolhimento e mediação intercultural.
\end{abstract}

PALAVRAS-ChAVE

Livro-álbum; identidade; diversidade; migração; mediação intercultural

\section{INTERCULTURAL MEDIATION THROUGH PICTUREBOOKS}

\begin{abstract}
Picturebooks are good resources for intercultural mediation with children given their multimodality and topic range related to contemporary living. When carefully selected, picturebooks may help children reflect on the multicultural world they live in and learn about meaningful intercultural action. Some examples of picturebooks are used from the Identity and Diversity in Picture Book Collections project (IDPBC) in order to explore topics related to the superdiversity of contemporary societies, such as, living in communities, multiple linguistic identities, approaches to mass migration and (voluntary and enforced) mobility. Fictional resources such as these are capable of generating empathy in readers and thus can be used to help children understand the growing cultural diversity around them, as well as the social phenomena of migration, refugees. These fictional resources may also contribute to children's understanding of social complexity at the global scale, at the human rights level, and within rules of democratic action as global citizens. Some inclusive didactic approaches are further suggested for using the selected picturebooks with five to 12-year old children in contexts of intercultural mediation.
\end{abstract}

KEYwORDS

Picturebook; identity; diversity; migration; intercultural mediation 


\section{INTRODUÇÃo}

Margaret Meek (1991) escreveu que somos as histórias que lemos ou contamos, no sentido em que as sociedades criam ficções e estas acabam por pautar o viver das pessoas em sociedade (Meek, 1991), reconhecendo igualmente a autora que a noção de que a ficção constrói a realidade poderá não ser confortável para a maioria das pessoas. No fundo, Meek concorre com outros autores para afirmar a ideia que as narrativas (ficcionais ou outras) que partilhamos são estruturas ideológicas ou estratégias utilizadas para construir a realidade, recordar o passado, apresentar quem somos, (a (s) nossa(s) identidade(s)), os modos culturalmente próprios de nos entendermos e de nos recriarmos, aos outros e ao mundo. Ler ou contar histórias são atos essenciais de produção de sentido, de nomear o que ainda não foi nomeado ou de (re)construir acontecimentos reais de outras maneiras, de modo a gerar sentidos alternativos. A escolha de uma história ou de um modo de a narrar representa consequentemente uma mundovisão, que tanto pode ser individual como coletiva. Segundo Bruner (1986), a narrativa configura um modo de pensar, geralmente recordado como vivido, sobre pessoas que são agentes, sobre as suas intenções e sobre as vicissitudes dessas intenções (Djikic, Oatley \& Moldoveanu, 2013, p. 30).

Convém, no entanto, alertar para riscos de utilização de ficções (e no caso do presente artigo, de livros-álbum) no quadro de representação cultural da diversidade. $\mathrm{Na}$ palestra intitulada The danger of a single story [O perigo da história única] (Adichie, 2009), um Ted Talk no qual a escritora nigeriana radicada nos EUA, Chimamanda Ngozie Adichie reiterava a importância de ler e contar histórias, no plural, ela alertava ao mesmo tempo para os perigos da "história única" e da reprodução de clichés, discriminação, preconceitos, estereótipos e populismo. $\mathrm{Na}$ base da sua palestra contra a discriminação étnica, racial e social, ela chama a atenção para a importância das histórias que se contam, que se publicam, que se leem na escola e fora dela e como elas configuram modos de representação das sociedades que se tornam dominantes, ao mesmo tempo que reduzem as experiências vividas na realidade a certos clichés.

Reproduz-se cultura com base no que se lê e ouve, pelo que é importante que se escolham histórias tendo em conta critérios de representatividade do que é narrado: como é que um determinado aspeto cultural é contado? Por quem? De que modo? Com que efeito? Dado que "não vemos o que não conhecemos", de que modo é que histórias (no plural) podem enriquecer o nosso conhecimento e reconhecimento da realidade representada?

Para além da necessidade de escolher criteriosamente as histórias sobre um determinado tópico ou tema que se conta ou lê a crianças, é igualmente importante considerar as estratégias da sua mediação intercultural junto de crianças, de modo a promover oportunidades de reflexão, de compreensão de fenómenos sociais complexos, sem desvirtuar a sua complexidade, e eventualmente promover o desenvolvimento das competências de que crianças necessitarão para lidar com situações de grande heterogeneidade cultural e linguística na escola - uma vez que estas são cada vez mais frequentes -, e de superdiversidade (Vertovec, 2006) nas sociedades. A superdiversidade étnica, social 
e linguística é um conceito convocado para descrever profundas alterações nos padrões migratórios que afetam a ideia de composição étnica homogénea de grupos de migrantes, a sua distribuição geográfica e o seu estatuto socioeconómico. O conceito visa relevar as diversas variáveis que se intersectam nas trajetórias de vidas sociais e culturais de migrantes nas sociedades atuais.

Neste texto debate-se, portanto, o potencial de utilização de livros-álbum para a mediação intercultural com crianças e jovens. A multimodalidade destes materiais de literatura infantojuvenil, quando criteriosamente selecionados e abordados de perspetivas socio construtivistas, tendo por foco a promoção da competência comunicativa intercultural e a cidadania global nos contextos educativos plurilingues e multiculturais das sociedades atuais, com as suas dinâmicas complexas de identidade e alteridade, permite uma formação explícita e intencional sobre o que acontece, quando no mundo globalizado do século XXI, as diversas populações e culturas do mundo contactam como nunca antes em termos de espaço e tempo, dada a mobilidade crescente dos povos, voluntária e/ou forçada, mas também à presença diária constante dos meios de comunicação digitais da Sociedade da Informação.

O nosso argumento para o presente texto é, em primeiro lugar, que a educação básica carece de novas mundovisões. E que estas podem ser partilhadas e aprendidas, de forma crítica, a partir de livros-álbum atuais. Estes não só têm evidenciado um crescente envolvimento com a representação de novas realidades de diversidade global e de ações humanas com implicações à escala global, de forma complexa, como possuem um potencial enorme de gerar empatia pelos outros, tornando-se assim em recursos úteis de educar para a diversidade e cidadania global.

Em segundo lugar, o presente texto argumenta que os livros-álbum, na sua multimodalidade, são instrumentos de desenvolvimento de multiliteracias, necessárias hoje para enfrentar um mundo que usa formas de representação complexas, baseadas tanto na oralidade, como na imagem e na escrita, por contraste com a tradicional literacia da escola, frequentemente ainda excessivamente ligada ao aprendizado e primado da escrita. Por outro lado, o livro-álbum, em que escrita e imagem se entrecruzam, abre perspetivas de relação do que a criança aprende na escola e usa em casa (televisão, telemóvel, tecnologias digitais). Contudo, dado que a introdução de livros-álbum na escola, sobretudo ao nível do pré-escolar, não constitui novidade, convém salientar que se advoga uma utilização destes recursos com crianças mais velhas e no quadro de pedagogias emergentes, socio-construtivistas, inclusivas, centradas no aluno, interativas e experienciais. Propõe-se um olhar sobre os livros-álbum como forma de mediar problemas sociais complexos em ambientes escolares e sociais com grande diversidade cultural e linguística, também por duas outras razões: porque as crianças começam por pensar por imagens e porque uma imagem não ergue as barreiras linguísticas de um texto escrito ou oral, sendo assim particularmente adequado para ambientes plurilingues.

Começaremos por uma definição necessariamente sumária de dois conceitos operacionais convocados para a narração de histórias em termos de competências a desenvolver em crianças: competência comunicativa intercultural e cidadania global. Estes 
dois conceitos e competências, refletidos nos currículos da educação básica, servirão para enquadrar as histórias de livros-álbum da coleção IDPBC (Identity and Diversity in Picture Book Collections) e as propostas inclusivas da sua exploração com crianças no contexto de propostas de mediação intercultural em salas de aula com significativa diversidade cultural e linguística, a partir de três objetivos educacionais: aprender a viver em comunidades culturalmente diversas, entender a construção de identidades linguísticas plurais e compreender a mobilidade e migração em termos atuais.

\section{EDUCAÇÃo PARA A CIDADANIA GLOBAL E DESENVOLVIMENTO DA COMPETÊNCIA COMUNICATIVA INTERCULTURAL}

Ao contrário do que acontecia há anos atrás, todas as crianças entram hoje frequentemente em contacto com comportamentos e manifestações culturais heterogéneos, tanto presencialmente como pelo que leem/veem nos meios de comunicação digitais. Para que o contacto se torne encontro e não choque (cultural), é necessário educá-las para tomar consciência, de forma crítica e conhecedora, do que as rodeia, para que possam desenvolver as capacidades, atitudes e conhecimento necessários à vida em (super) diversidade, saibam comunicar com eficácia em ambientes linguística e culturalmente diversos (ou seja, desenvolvam competência comunicativa intercultural) e saibam construir uma cidadania global.

\section{Cidadania global}

A cidadania global é um termo frequentemente contestado, dada a sua abrangência de utilização e ambiguidade. Oxley e Morris (2013, p. 301) salientam como é fácil usar este conceito para situações tão diferentes como banir o uso do véu sobre a cara das mulheres em sociedades ocidentais; promover o trabalho com a diferença que se origina em divisões religiosas; desmontar o ponto de vista hegemónico das sociedades ocidentais sobre o resto do mundo; ou capacitar os cidadãos com as competências que Ihes permitirão resolver conflitos e lutar contra a injustiça social.

Sendo a cidadania um objetivo da educação básica, também nem sempre se aborda a sua dimensão como 'global', dado que muitas vezes se procura ligar este termo (cidadania) com a educação para o desenvolvimento, com a aprendizagem dos direitos humanos, ou com a educação para a paz (Oxley \& Morris, 2013, p. 302).

Contudo, é no conceito de construção de uma cidadania global que se pretende situar a presente abordagem de mediação intercultural com livros-álbum. Utilizaremos a noção convocada por Parekh (2013, p. 12) de um cidadão orientado para a globalidade, portanto geograficamente localizado num território específico, embora atento às repercussões locais no global e vice-versa. Consideraremos igualmente como parte da cidadania global as competências geralmente definidas, de forma normativa em contextos educativos, que presumem a formação de um cidadão em tempos de grande diversidade cultural e linguística: tomar consciência de si no mundo; tomar consciência da 
responsabilidade humana sobre o planeta, conhecer outras culturas; desenvolver empatia e responsabilidade pelo outro à escala global.

\section{COMPETÊNCIA COMUNICATIVA INTERCULTURAL}

Nas competências educativas enunciadas no ponto anterior enquadra-se frequentemente a educação intercultural, no sentido de promover junto das crianças o autoconhecimento de si para responder de forma adequada aos outros em encontros interculturais, mas também tomar consciência de como cada indivíduo vai construindo múltiplas identidades, flexíveis, e sempre em mudança (Sen, 2006).

Em Organização curricular e programas. Estudo do Meio (Ministério da Educação, s.d., pp. 100-114), referente ao 1. ${ }^{\circ}$ ciclo, por exemplo, fala-se em "desenvolver o respeito pelos outros povos e culturas, rejeitando qualquer tipo de discriminação" (Ministério da Educação, s.d., pp. 103-104). Refere-se a descoberta dos outros por meio de "conhecer costumes e tradições de outros povos quando existem realidades na escola" (Ministério da Educação, s.d., pp. 113-114). E, do programa do $3 .^{\circ}$ ano consta a formulação seguinte: "conhecer aspetos das culturas das minorias que eventualmente habitem na localidade ou bairro (costumes, língua, gastronomia, música)" (Ministério da Educação, s.d., p. 108).

Contudo, a competência comunicativa intercultural, que nos parece ser a necessária à eficácia de comunicação num mundo globalizado e numa escola diversa, irá para além do conhecer, para abarcar o saber ser, saber relacionar-se de forma crítica com os outros e saber aprender no sentido da descoberta e da interação com os outros (Byram, 1997). O modelo de Byram (1997) de competência comunicativa intercultural poderá ser sintetizado na capacidade manifesta dos alunos para trabalhar e colaborar de forma efetiva com crianças e jovens de outras culturas. Tal implica utilizar comportamentos comunicativos adequados e saber negociar entre as diferentes identidades em presença em ambiente culturalmente diverso. A competência comunicativa intercultural inclui a tomada de consciência intercultural, o desenvolvimento da sensibilidade intercultural e a aprendizagem da eficácia intercultural.

Uma das escalas usadas para medir a Eficácia Intercultural, a de Portalla e Chen (2010; (ver também Mendenhall, Stevens, Bird, Oddou \& Osland, 2011), um instrumento validado que avalia a capacidade dos indivíduos para atingir objetivos comunicativos em interações interculturais, inclui parâmetros que medem o interesse e a curiosidade pelas pessoas de outras culturas, bem como o interesse em ser bem compreendido (dimensão de aprendizagem contínua, subdividida em consciência de si e exploração); o interesse em compreender outros povos e em desenvolver e manter relações com pessoas diferentes de nós (dimensão de envolvimento interpessoal, subdividida em mentalidade global e interesse pela relação); e compreender as diferenças psicológicas e emocionais que nos podem auxiliar a encontrar pontos de contacto, diminuindo assim o esforço psicológico requerido na interação com pessoas diferentes de nós (dimensão de resistência, subdividida em visão positiva e resiliência).

Quando traduzida para ações concretas em sala de aula, a dimensão de eficácia intercultural ou de desenvolvimento da competência comunicativa intercultural requer que 
as atividades de aprendizagem configurem explicitamente diversas perspetivas sobre um mesmo tópico, tornando possíveis trocas de impressão sobre perspetivas diferentes. Requer porventura também que os diversos materiais e recursos que configuram perspetivas diferentes sobre um tópico sejam conjugados com dinâmicas inclusivas de sala de aula que permitam que todos contribuam com o seu ponto de vista; requerendo igualmente que, quando possível, os grupos de trabalho sejam oriundos de proveniências diversas ou possuam experiências de contextos diferentes (Gregersen-Hermans, 2015, p. 47).

Contudo, persistindo ainda dúvidas sobre a eficácia intercultural quando promovida por meio de textos ficcionais, convém salientar os resultados publicados sobre o aumento de sensibilidade intercultural derivado da leitura de ficção. O estudo recentemente publicado por uma equipa de investigadores da Universidade de Toronto, Djikic et al. (2013), conclui que os participantes (estudantes universitários), que não revelavam grande abertura de espírito inicialmente e que leram pequenas ficções, por contraste aos que leram ensaios não-ficcionais, mostraram maior abertura de espírito após a leitura de ficção. Embora a leitura de não-ficção permita aprender sobre qualquer matéria, nem sempre ajuda o leitor a pensar sobre ela. Um texto ficcional, sendo, em essência, uma narrativa sobre o mundo social, sobre indivíduos que interagem no mundo social, aumenta a empatia cognitiva dos leitores, ou seja, a sua capacidade para pensar em termos sociais e o seu interesse emocional. A empatia foi medida neste estudo em termos de capacidade do leitor para adotar o ponto de vista do outro (empatia cognitiva); e sentir compaixão pelos menos afortunados (empatia emocional).

Embora não se possam extrapolar diretamente estes dados para a leitura de crianças, ou sustentar que estes efeitos de maior abertura e empatia para com o outro se mantém de forma constante ao longo do tempo, os dados abrem perspetivas interessantes sobre o lugar da leitura da ficção na criação de atitudes de relação empática com o outro. No campo da educação pela literatura e no contexto de dinamizações em torno de ficções com crianças, os dados apresentados conduzem-nos a práticas de exploração da ficção que permitam aos jovens leitores uma identificação com a mundovisão, os objetivos e as intenções de protagonistas, que manifestem a sua simpatia por determinadas personagens, ou que debatam a sua aproximação às experiências narradas como se tivessem tomado parte nelas. Djikic et al. (2013, p. 33) relevam ainda as funções de simulação das narrativas ficcionais por permitirem aos leitores imaginar mundos possível e desfechos prováveis, bem como compreender emoções dos outros e procurar compreender o que os outros (as personagens) estão a pensar e sentir. A investigação levada a cabo por Speer, Reynolds e Zacks (2009) permite mesmo afirmar que ler as simulações de uma história envolve as mesmas estruturas cerebrais usadas para ações e perceções comparáveis na vida real (Speer et al. 2009, p. 33), sem porventura os impactos negativos de incompreensões e choques culturais.

Os estudos nesta área com crianças do pré-escolar relacionam as histórias que Ihes foram lidas e os filmes ficcionais que viram como significativos em termos do desenvolvimento da empatia nestas idades, por oposição, por exemplo, a ver televisão (Speer et al., 2009, p. 34). 


\section{IMAGINAR O MUNDO GLOBAL E PERCEBER COMO SE FORMAM IDENTIDADES LINGUÍSTICAS}

São diversos os tópicos do currículo do ensino básico que permitem desenvolver a competência de cidadania global, normativa e experiencial, bem como a competência comunicativa intercultural, embora nem sempre os materiais pedagógicos propostos respondam aos enunciados acima propostos e raramente se utilizem livros-álbum com estes objetivos.

Para uma proposta de mediação intercultural, que tanto pode ser levada a cabo por professores como por educadores sociais, propõe-se a identificação de tópicos englobantes, em torno dos quais se definem objetivos de aprendizagem. Como exemplo de utilização dos livros-álbum da coleção IDPBC sugerimos trabalhar um tópico ligado às questões do local em articulação com o global, nomeadamente Imaginar o mundo global e, dentro deste, colocar o enfoque na construção de identidades linguísticas das pessoas, para evidenciar que as identidades linguísticas são construídas e que um indivíduo tem múltiplas identidade(s) linguística(s).

A escolha de tópico para desenvolvimento de atividades de mediação intercultural com livros-álbum determina abordagens pedagógicas e estratégias de dinamização que exploram a diversidade linguística e o mundo global/globalizado de forma construtiva no processo de ensino e aprendizagem, com todos os alunos, valorizando a sua diversidade cultural e linguística como enriquecedora para a comunidade educativa.

Não se trata, contudo, de um tópico de fácil abordagem, dada a crescente multiculturalidade e plurilinguismo nas escolas e a necessidade que toda a comunidade educativa sente de compreender as crianças e jovens de culturas diferentes, com línguas diferentes e experiências educativas prévias muito diversas também.

No entanto, prevendo-se mobilidades crescentes à escala global, tanto voluntárias como involuntárias, a escola não se pode alhear da sua realidade multicultural e plurilingue, nem esquivar-se à necessidade dos jovens de aprender diversas línguas ao longo da vida para viajar, aprender, trabalhar e viver em ambientes que, mesmo em contextos de culturas monológicas dominantes, serão crescentemente mais internacionais e multilingues; mas também porque o acesso crítico à informação digital e multimédia, a liberdade de expressão (de consumo e de produção de conteúdos) e a capacitação de uma voz audível no mundo globalizado (Unesco, s.d.) passam pelo domínio de certas línguas de influência.

A escolha do tópico anuncia igualmente uma chamada de atenção para a frequente marginalização das questões linguísticas de comunicação eficaz na mediação intercultural, como se língua e cultura pudessem ser tratadas de forma separada. A mediação intercultural é essencialmente também sempre comunicação intercultural. E esta pode ser facilitada de muitos modos diferentes: quer pela utilização de estratégias de comunicação eficazes como pela escolha de recursos adequados e seleção de estratégias de ensino/aprendizagem mais conducentes à comunicação eficaz entre pessoas de culturas diversas. Entre estas estão a exploração criativa dos recursos, exercícios comparativos e de contraste da informação veiculada e da configuração dos recursos. A comunicação intercultural também pode passar pela introdução de práticas experienciais (virtuais, 
reais ou ficcionais) sobre outras culturas, pessoas e lugares. Pode haver trocas de informação e de conhecimento, desde cedo, entre jovens de culturas diversas, por meio de recursos digitais, como acontece com a plataforma e-twinning, por meio de projetos de telecolaboração (trocas virtuais online) ou por intermédio de visitas de estudo e períodos de estudo no estrangeiro.

\section{REPRESENTAR A SUPERDIVERSIDADE}

Torna-se necessária uma pequena contextualização à identificação de quais os argumentos subjacentes a uma mediação intercultural com livros-álbum centrada no tópico "Imaginar o mundo global e perceber como se formam identidades linguísticas".

A emergente comunidade mundial (Israel, 2012, p. 79), com a deslocação global de pessoas e o declínio de comunidades homogéneas, dá origem a enquadramentos educativos novos, necessariamente assentes em intercâmbios, trabalho entre pares, colaboração e cooperação, trabalho interdisciplinar e novas configurações do lugar ocupado pelas línguas e outras disciplinas na educação, mas sobretudo nas competências a desenvolver para sobreviver no mundo.

Os problemas mais prementes radicam em padrões sociais e demográficos emergentes em muitos países europeus. Estes pressionam as conceções que os trabalhadores sociais e o público em geral detém sobre imigrantes e sociedades multiculturais. Os problemas emergentes derivam da nova complexidade de presença nos territórios de novos migrantes, ou estrangeiros, em pequenos grupos, dispersos, de origens múltiplas, provavelmente com conexões transnacionais, socioeconomicamente diferenciados em termos do seu estatuto legal (trabalhadores temporários, turistas, portadores de vistos especiais, quadros de empresas multinacionais, refugiados, imigrantes, alunos estrangeiros, pedidos de asilo, etc.).

Os problemas emergentes são frequentemente de natureza linguístico-cultural (utilizadores de diversas línguas-culturas no mesmo espaço e necessidade de comunicar no quadro da diversidade cultural) como expressão da superdiversidade (Vertovec, 2006), um termo cunhado para refletir a diversificação de etnias e de países de origem dos migrantes, mas também de variáveis de como, onde e com quem vivem esses migrantes, as suas afiliações religiosas, identidades regionais e linguísticas no país de origem, afiliações politico partidárias e muitos outras identidades forjadas a partir de grupos de pertença. Existem diferenças de estatuto, direitos, experiências laborais, de género, de relação com a espacialidade entre os migrantes que se tornaram socialmente significativas em termos das respostas esperadas pelos serviços públicos. Só em escolas de Londres, segundo o autor, baseando-se em Baker e Mohieldeen (2000), para dar um exemplo, falar-se-iam 300 línguas (um número baseado num universo escolar de 896.743 alunos e nas línguas por eles faladas em casa), o que coloca uma enorme pressão nas escolas, autarquias e outros serviços públicos. À superdiversidade linguística carece acrescentar outro dado, o da grande variabilidade de diversidade religiosa, por exemplo, dentro do grupo dos muçulmanos, devido à sua proveniência; ou o facto de as 
práticas transnacionais dos migrantes serem mais diversas, mais intensas e mais complexas do que no passado (Vertovec, 2006). Segundo o autor, existe o risco acrescido de grupos a viver vidas paralelas sem relações interculturais significativas num mesmo território (Vertovec, 2006, p. 27).

Pelo conjunto das razões apontadas, a escolha de livros-álbum para abordar esta faceta deste tópico foi feita pensando na representação de bairros mistos, em que as pessoas se encontram umas com as outras nos seus hábitos rotineiros (deslocações, compras, escolas). Estas serão ideias valiosas para mostrar como diversas variáveis, nomeadamente etnia, estatuto social, género, idade, localidade, se intersectam em contextos de práticas quotidianas.

\section{REPRESENTAR A PLURALIDADE LINGUÍSTICA}

Uma das estratégias usadas para fazer face à superdiversidade é a preservação e promoção de políticas plurilingues (aprendizagem e ou valorização do conhecimento de diversas línguas ao longo da vida). Esta promoção é acompanhada de estratégias de coesão e inclusão sociais: aceitar, valorizar e interagir com pessoas que são diferentes de nós.

Contudo, o uso de uma língua franca de comunicação, como o Inglês, é geralmente uma estratégia concomitante, por permitir uma certa unidade linguística, sendo esta uma das razões para a introdução da sua aprendizagem curricular como língua estrangeira desde $03 .^{\circ}$ ano de escolaridade em escolas portuguesas.

Pode-se olhar para a hegemonia do Inglês no mundo como uma estrutura de domínio linguístico, mas pode-se também considerá-lo uma língua conectada a uma multitude de identidades linguísticas, já que o Inglês, sendo a língua estrangeira mais aprendida no mundo, será frequentemente usado como mediador entre línguas maternas em contextos internacionais ou de grande diversidade linguística (Breidbach, 2003).

As questões políticas, económicas, sociais, culturais, ecológicas, tecnológicas mais importantes, no sentido em que afetam a vida das pessoas localmente, são hoje decididas ao nível global, não podendo ser contidas geográfica ou socialmente. As constelações de participação a nível local, nacional e supranacional pressupõem uma consciência linguística apurada, de que língua usar e como interagir com falantes de outras línguas em termos de igualdade e de valorização das suas próprias múltiplas identidades linguísticas e das dos outros.

Uma sociedade plural, diversa e intercultural cuida de promover a transmissão de ideias, opiniões e perspetivas sobre a realidade, por mais diversas que se revelem. Uma educação plurilingue, intercultural e para a diversidade terá de centrar-se essencialmente na aceitação e integração de uma multiplicidade de novas experiências (ditadas pelas circunstâncias e necessidades de grupos, culturas e identidades diversas), que tanto podem ser do domínio privado (a família, os amigos, as atividades quotidianas, as formas de comunicação), como do domínio público (por exemplo, ser aluno numa escola).

Assim sendo, a escolha de livros-álbum foi pensada para representar identidades linguísticas diversas como forma de representar uma mundovisão e de fomentar a 
competência cultural múltipla, práticas interlínguas (Rampton, 2005) e experiências de multilinguismo (Harris, 2003).

\section{MÚLTIPLAS HISTÓRIAS SOBRE UM MESMO TÓPICO: MIGRAR}

No concreto das suas vidas, as crianças são confrontadas com imagens e histórias diversas de migrantes, refugiados, familiares em mobilidade geográfica, por razões diversas. Podem tratar-se de histórias únicas, que simplificam situações complexas, vilipendiando-as, ou de imagens isoladas, difíceis de interpretar, por falta de informação contextual.

Para representar a complexidade atual, a mobilidade humana deve ser encarada como situação de encontro cultural, que tanto pode ser negativa como positiva, no sentido em que é um motor de inovação e criatividade; o encontro intercultural tanto resulta em choque como em interseção de grupos e de culturas, que dão origem a novas reconfigurações; o encontro intercultural tanto pode causar a segregação, o conflito e a guerra, como potenciar novos modos de vida, criativos e inovadores.

O conceito de mobilidade, perspetivado deste modo, é também adequado para perceber que as identidades individuais e de grupo se encontram em fluxo permanente, intersetando-se em espaços, no tempo (histórico) e na imaginação.

Assim sendo, é importante que os livros-álbum permitam explorar os encontros interculturais e as mobilidades contemporâneas em histórias diversas, dando exemplos de continuidade com o passado, mas também de disjunção. Tal como é da maior relevância levar as crianças a perceber que os livros-álbum são práticas culturais entre adultos e crianças e formas de comunicar e de imaginar a sociedade. Nesse sentido contribuem para a formação político-ideológica de certas ideias e sentidos (Lewis, 2002).

\section{OS LIVROS-ÁLBUM SELECIONADOS}

A utilização de imagens e ilustrações sob a forma de narrativas, por exemplo em livros-álbum e narrativas gráficas, tem sido amiúde usada em diversos contextos europeus como estratégia de aproximação das crianças migrantes e oriundas de minorias étnicas às múltiplas representações das sociedades que habitam e ao capital social da escola. Um dos exemplos mais mediatizados terá sido o de uma Biblioteca para Lampedusa de silent books, livros-álbuns só de imagens, intitulada Silent books: final destination Lampedusa'.

Que linguagem será mais expressiva para uma criança do que uma sucessão de imagens numa narrativa (com ou sem texto), permitindo-lhe a construção e reconstrução das suas vivências, a par de tentativas de interpretação do que vê representado a partir dos seus próprios conhecimentos culturais (implícitos e explícitos) e dos repertórios linguísticos que domina?

' Disponível em http://www.ibby.org/awards-activities/activities/silent-books/ 
As imagens visuais dominam as aprendizagens iniciais das crianças, as suas emoções e a sua mundovisão, pelo que a(s) sua(s) literacia(s) se encontra (m) profundamente entrosada(s) no modo como aprendem a ver e o que esperam ver (Meek, 1991). Tal como precisam de aprender a ler, as crianças precisam de aprender a ver as imagens de um livro-álbum; sem instrução explícita não as compreenderão. As imagens de um livro-álbum não são apenas ilustrações do texto que as acompanha; são uma forma distinta de representação, assente em códigos semióticos que têm tanto a ver com o mundo da literatura como com o da televisão, do filme e da produção visual digital.

Como escreve Meek (1991), a utilização de livros-álbum presume que vivemos numa cultura em que as imagens visuais e as narrativas são modos normais de organizar o mundo; em que os livros destinados a crianças, como os livros-álbum, transvasam para outros públicos; em que se debate a transferência de uma literacia baseada na escrita e leitura, para multiliteracias e a necessidade de modos de aprender a ler o visual e as convenções narrativas transculturais (variedades de discursos, modos de saber, apresentar e representar, articulações diversas do mundo e dos seus problemas).

Ao criarem-se condições de interação cultural da criança com as imagens num livro-álbum desenrola-se um exercício de aceitação mútua e de integração do capital cultural representado e do próprio capital cultural da criança, que estão na base da prevenção da segregação e do isolamento ou fechamento em si daqueles que não veem as suas experiências (ou as suas línguas) reconhecidas nos meios de comunicação usados na escola.

\section{IDENTIDADE E DIVERSIDADE EM LIVROS-ÁLBUM: A COLEÇÃO IDPBC}

A proposta pedagógica de mediação intercultural que apresentamos tem por base uma coleção internacional de livros-álbum, Identity and Diversity in Picture Book Collections. O projeto IDPBC desenvolveu um catálogo anotado de 24 livros-álbum para crianças dos cinco aos 12 anos sobre o tema da identidade e da diversidade, disponível online sob a forma de flip book ${ }^{2}$. O catálogo reúne um conjunto de livros-álbum internacionais atuais (grande parte deles acessível online, em parte ou na totalidade), com potencial educativo de desenvolvimento das competências acima descritas. A coleção de livros-álbum e as propostas de dinamização pedagógica desses livros com crianças visa dotar educadores, professores e técnicos de serviço social das competências para mediar as novas realidades junto de crianças e jovens por meio de atividades de educação formal, não formal e informal (redes familiares, sociais).

Os livros-álbum, por contraste com outros materiais ficcionais, aportam benefícios diversos a diferentes grupos de alunos e em particular a pré-leitores ou leitores relutantes (Botelho \& Rudman, 2010; Cotton \& Daly, 2014; Roche, 2010, 2015), porque as representações visuais se abrem mais facilmente, do que o texto verbal, a interpretações polifónicas, baseadas na experiência de cada leitor.

${ }^{2}$ Disponível em http://www.diversitytales.com/flipbooks/bookcollection/

Annotated bibliographic catalogue. Disponível em http://diversitytales.com/flipbooks/bookcollection/files/assets/basic-html/page-1.html

Guide for enhancing inclusive practices. Disponível em http://diversitytales.com/resources/IDPBC_Guide.pdf 
Graham (1990, p. 27) salienta que a criança lê as imagens de um livro-álbum á semelhança de como interpreta comportamentos na vida real, adquirindo informação sobre como vivem e interagem pessoas de diferentes culturas e apoderando-se intrinsecamente das diferentes formas de cultura e de interação. Baghban (2007, p. 71) reconhece no livro-álbum o potencial de ajudar crianças migrantes a lidar com os desafios que enfrentam, como, por exemplo, relacionar-se com gerações mais velhas e com tradições, manter elos de ligação com os familiares distantes e preservar construtivamente as suas relações com a terra natal. Tal será particularmente importante num mundo multicultural globalizado e tecnológico que assiste a mobilidades voluntárias e involuntárias massivas.

De seguida realçaremos aqueles livros-álbum que poderiam servir para abordar o tópico de mediação intercultural acima definido a partir dos critérios que particularizámos, nomeadamente: a representação de bairros multiculturais e multiétnicos em que as pessoas se encontram umas com as outras nos seus hábitos rotineiros (deslocações, compras, escolas), ativável em Last stop on market street (de la Pena \& Robinson, 2015) e We are all born free (Amnistia Internacional, 2015); a representação de múltiplas identidades linguísticas que pode ser bem documentada por My two blankets (Kobald \& Blackwood, 2014); e a representação de múltiplas histórias sobre migração configurada em quatro livros-álbum: Migrando (Mateos, 2010), Azzi in between (Garland, 2012), Akim court (Dubois, 2012) e The island (Greder, 2008).

Na secção seguinte apresenta-se sumariamente cada livro-álbum e algumas sugestões de dinamização dos livros-álbum com crianças.

\section{DINAMIZAÇÕES INTERCULTURAIS}

Porque sabemos que o acesso aos materiais não é suficiente para apoiar os atores educativos na promoção da educação para o século XXI, gostaríamos de propor algumas estratégias inclusivas de mediação dos livros-álbum transversais a qualquer livro-álbum, a saber: relacionar o texto visual com a experiência pessoal da criança; ajudá-la a encontrar a sua voz para expressar uma opinião sobre o que está a ver. Permitir à criança que use diversas linguagens para expressar o seu entendimento (verbais, visuais, cinéticas); convidar as crianças a reagir ativamente ao que estão a ver no livro; explorar os temas, os tópicos e as ideias suscitadas pelo livro-álbum com as crianças a partir de perspetivas diversas e múltiplas.

Se queremos ajudar a desenvolver nas crianças uma cidadania global e uma competência comunicativa intercultural, importa capitalizar sobre um aspeto muito importante: as crianças pensam em imagens, primeiro, e só depois por palavras. As imagens são a primeira linguagem que ajuda a promover um encontro com a história, particularmente quando as crianças ainda não dominam a língua do país de acolhimento.

Contudo, a relação da criança com a imagem não é espontânea; ela tem de ser dirigida e acompanhada, pelo que propomos, depois de apresentados os livros-álbum, um conjunto de perguntas para ativar a leitura de imagens. 


\section{CONVIVÊNCIA COSMOPOLITA}

Comecemos pela representação de bairros mistos em que as pessoas se encontram umas com as outras nos seus hábitos rotineiros (deslocações, compras, escolas) em Last stop on market sreet (de la Pena \& Robinson, 2015) e We are all born free (Amnesty International, 2015), estabelecendo a normalidade da vida multicultural e diversa.

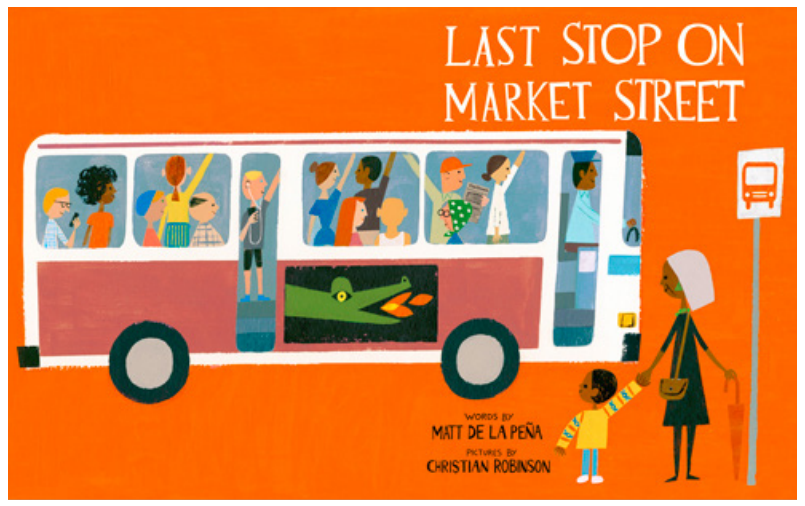

Figura 1: Capa de Last stop on Market Street

Fonte: de la Pena e Robinson (2015)

Last stop on Market Sreet (2015), de Matt de la Pena e Christian Robinson, conta a história de uma criança afro-americana que apanha um autocarro com a avó; pelo caminho C) pergunta porque é que não tem um carro como o do seu amigo Colby; porque é que não tem um IPod como os rapazes no autocarro, etc. e a cada pergunta a avó responde com humor, fazendo-o valorizar o que tem em seu redor, especialmente as pessoas. No autocarro conversam com um homem invisual, assistem a um concerto de viola, e seguindo atrás de um homem incapacitado e de um sem-abrigo, acabam por chegar ao seu destino, a cozinha onde avó e neto prestam serviço voluntário.

Sugestões de exploração: O que significa 'beleza interior'? Procura em teu redor o que normalmente não interpretas como belo e desenha esses objetos numa tira de papel.

Ou: Onde podes oferecer-te para fazer trabalho voluntário como o de Cl e Nana? Pode ser junto da tua família...

Ou: Como é que a diversidade pode tornar a tua comunidade mais forte?

Prepara um livro sobre a diversidade da tua comunidade.

We are all born free, produzido pela Amnistia Internacional, é a Declaração dos Direitos Humanos, ilustrada por 30 dos maiores ilustradores do mundo. A variedade de estilos de ilustração explora a condição humana em diferentes contextos e situações, promovendo uma consciencialização dos direitos humanos no concreto da atuação de crianças em cada cena ilustrada. As ilustrações por si são pretextos para debate e exploração 
das razões por que as pessoas possuem origens diversas, quais são as caraterísticas comuns de certos grupos, o que há de diversos e igual, ou como respeitar a diferença.

Sugestões de exploração: Criar histórias a partir de cada ilustração; ilustrar os direitos humanos; adotar papéis a partir das personagens representadas e criar diálogos encenados.

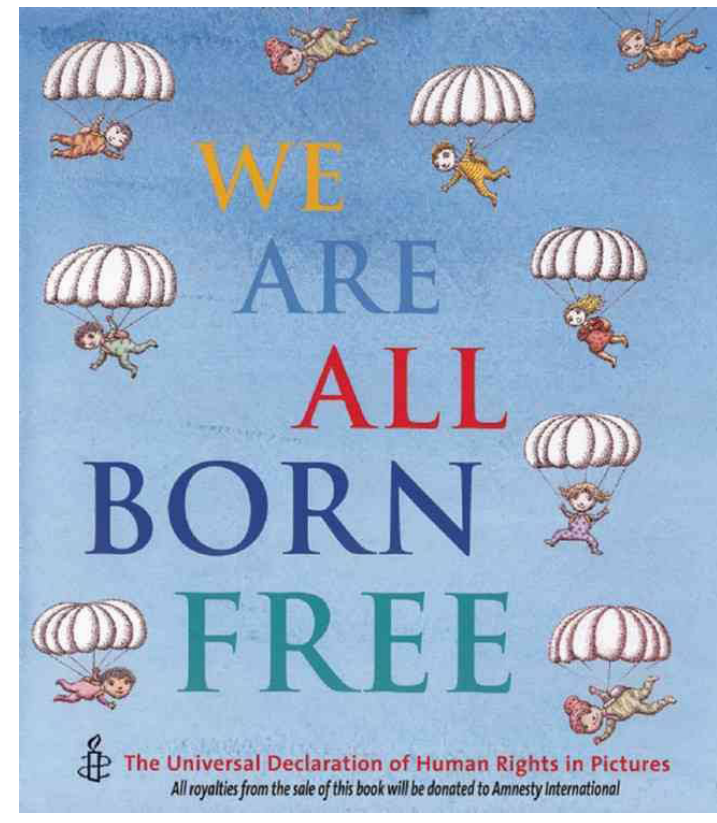

Figura 2: Capa de We are all born free

Fonte: Amnistia Internacional, 2015

\section{A CONSTRUÇÃo DE IDENTIDAdES PLURILINGUES}

Para a compreensão de identidades linguísticas, como se formam, por que se formam e o que implicam convocámos o livro-álbum de Irena Kobald, ilustrado por Freya Blackwood, intitulado My two blankets (2014).

My two blankets (Kobald \& Blackwood, 2014) conta a história de uma rapariga recém-chegada de uma cultura reconhecivelmente (pelos tons ocre e laranja e formato das casas em palhotas) africana, por questões alegadamente de segurança, a uma urbe provavelmente europeia (representada em tons frios de azul claro e cinzentos e alguns beges), onde se sente estranha: tudo é estranho, a comida, os animais, as plantas, o vento. A torrente de palavras estranhas que a rodeiam é tão forte que ela se sente aniquila$\mathrm{da}$, pelo que se refugia no seu velho cobertor, coberto de representações de objetos que Ihe aportam segurança; ali se sente segura, ao ponto de não querer sair para o exterior. Quando passeia pelo parque pela terceira vez dá-se o encontro com uma rapariga local, cuja língua desconhece, mas cujo sorriso reconhece. Começa assim uma amizade, que não apaga, porém, a tristeza e solidão que sente, até que a outra rapariga lhe começa a 
trazer palavras novas, sempre mais. No cobertor da protagonista começam a aparecer algumas dessas novas palavras, que começam a deixar de ser sentidas como frias e duras. O novo cobertor começa por ser pequeno e fino, mas começa a crescer, a crescer até se tornar tão confortável, suave e quente como o anterior, até ela deixar de se importar com qual o cobertor que usa.

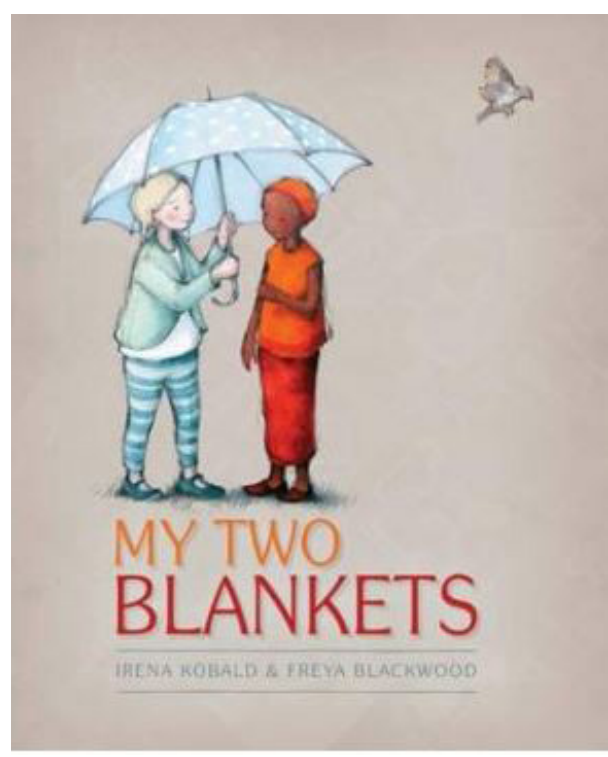

Figura 3: Capa de My two blankets

Fonte: Kobald e Blackwood, 2014

Como estratégias de exploração, sugerimos: Como te sentirias se tivesses de permanecer num outro país durante um longo período de tempo? Olha para a contracapa do livro e escolhe os objetos que seriam importantes para ti. Quais levarias contigo se só pudesses levar 10?

Ou: O que é um cobertor? Para que serve? Como te sentes com um cobertor? Todos se sentem da mesma maneira?

Ou: Compara o cobertor que a protagonista acha confortável e em que dorme com o novo cobertor que ela cria: tem a mesma forma? E as cores, são as mesmas? E os objetos representados, são os mesmos?

Ou: Desenha um cobertor para a tua língua materna: pensa na forma, cor e objetos que desenharias nele. Em seguida desenha um cobertor para uma outra língua que saibas: pensa outra vez na forma, cor e objetos que desenharias nele. Compara os teus cobertores com os dos teus colegas: O que acrescentarias aos/tirarias dos teus cobertores? 


\section{Perspetivas Sobre migraÇão e mobiliddade}

Será relevante debater com crianças os direitos humanos e dos imigrantes e refugiados, ou os pedidos de asilo? Pensamos que sim, dada a prevalência de situações dessa natureza que rodeiam as crianças e dado que todas elas já experimentaram momentos de injustiça, de preconceito, de conflito, de necessidade de tomar uma decisão contrária à da maioria ou de se deixar conduzir pelas opiniões maioritárias.

Os quatro livros-álbum seguintes apresentam e representam diversas perspetivas sobre os tipos de mobilidade humana a que assistimos hoje: voluntária, em busca de trabalho ou de uma vida melhor, em fuga de conflitos armados, da perspetiva de quem chega a um território e de quem foge de um território, com finais felizes, menos felizes e sombrios, em estilos visuais muito diferenciados, de autores de origem linguística diversa, e formatos de livro-objeto variados: capas duras e moles, maiores e mais pequenos, fazendo uso de uma paleta grande de cores, ou apenas de cores primárias, ou de gradações entre o branco e o preto, em quadradinhos, em esboço a lápis, etc.

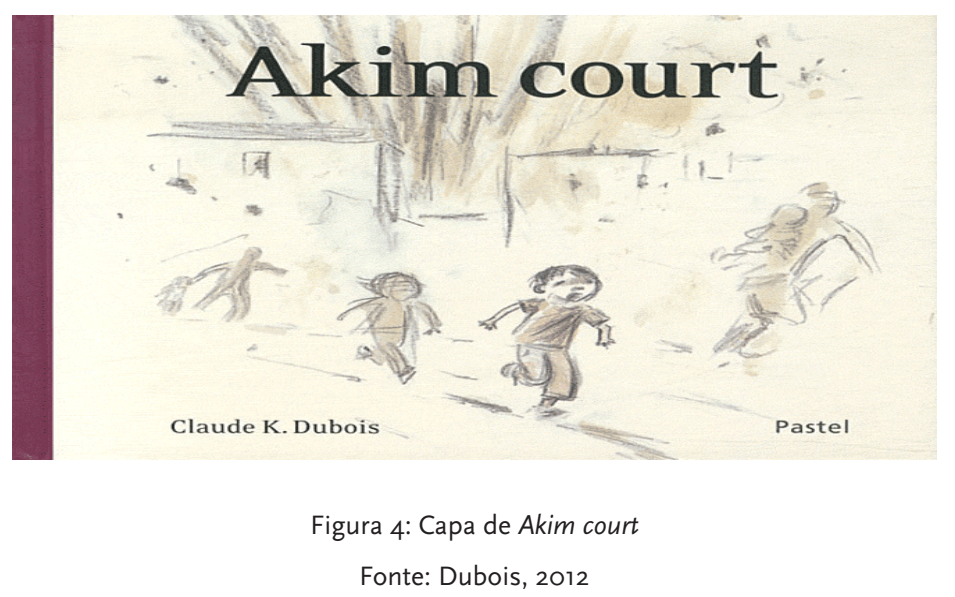

Akim court, de C. K. Dubois (2012), conta a história de uma criança que foge de um conflito armado, é presa por soldados e acaba por chegar a um campo de refugiados. Akim é colocado na situação de uma criança perdida numa zona de guerra: experimenta a violência, a perda, a alienação e o drama de se tornar refugiado, quando inicialmente era apenas uma criança a brincar à bola com outras, à porta de casa. Ao longo da narrativa, Akim agarra-se à ligação familiar com a mãe, procurando e encontrando proteção momentânea junto de outras mulheres, também elas em fuga com os filhos. Uma história predominantemente visual, a carvão, com momentos verbais de síntese.

Azzi in between, de Sarah Garland (2012), é a história de como uma família migrante (pai, mãe, filha), após uma terrífica viagem de carro e barco, se tenta adaptar a um novo ambiente cultural. É preciso aprender uma nova língua, encontrar um lar e voltar de novo à escola. Azzi aprende a nova língua, faz uma amiga, reconhece que outras crianças partilham histórias iguais à sua, e mantém-se agarrada à sua cultura, pois guarda consigo uma semente que acaba por germinar na nova casa. Esta é uma história que encoraja no leitor uma resposta emocional sobre o medo, a separação, a perda, a esperança e a capacidade para recomeçar. 


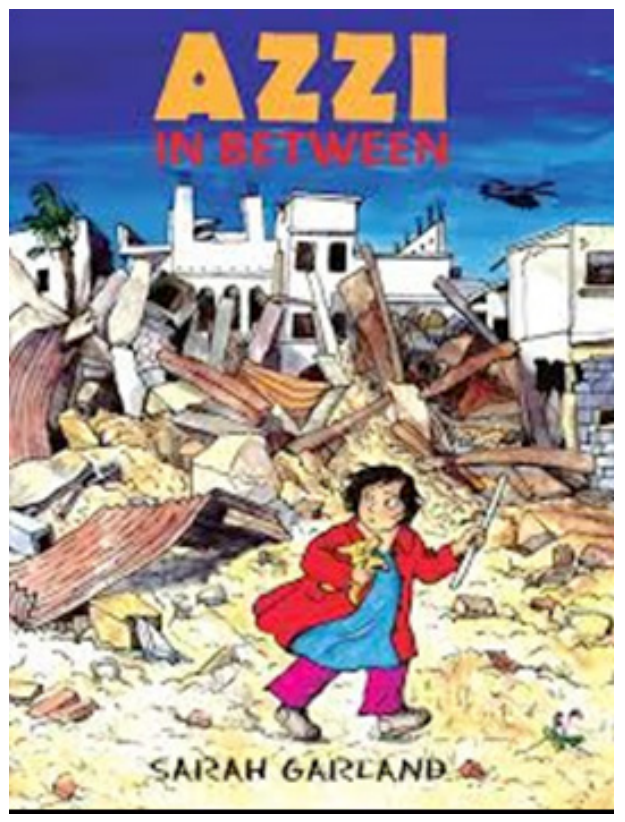

Figura 5: Capa de Azzi in Between

Fonte: Garland (2012)

Migrando, de Mariana Chiesa Mateos (2010), é um álbum sem palavras (para além do título), que conta uma história de migração num sentido do folhear das páginas até ao meio do livro e outra história de fluxo migratório do final até ao meio, obrigando o leitor a inverter o livro. Não se restringe às migrações humanas, incluindo bandos de aves migratórias antropomorfizadas, diversos meios de transporte (comboio, avião, barco) e emoções à chegada e à partida.

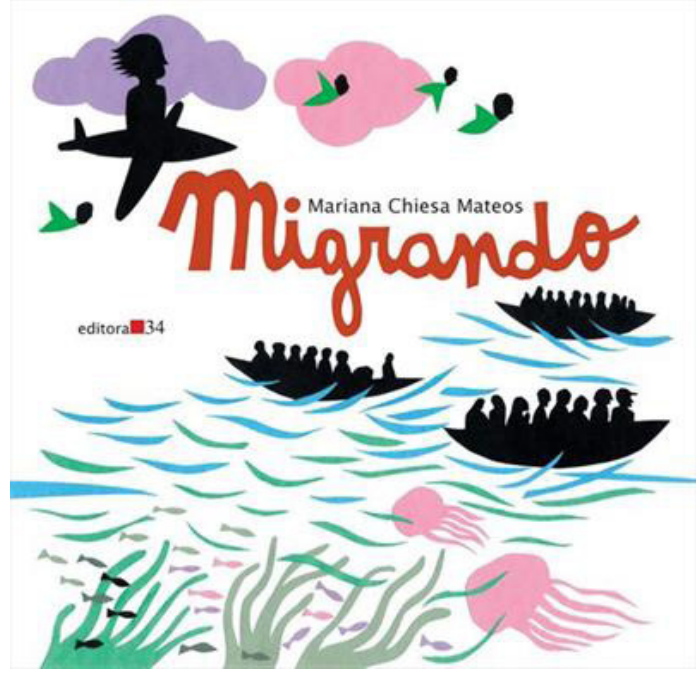

Figura 6: Capa de Migrando

Fonte: Mateos, 2010 


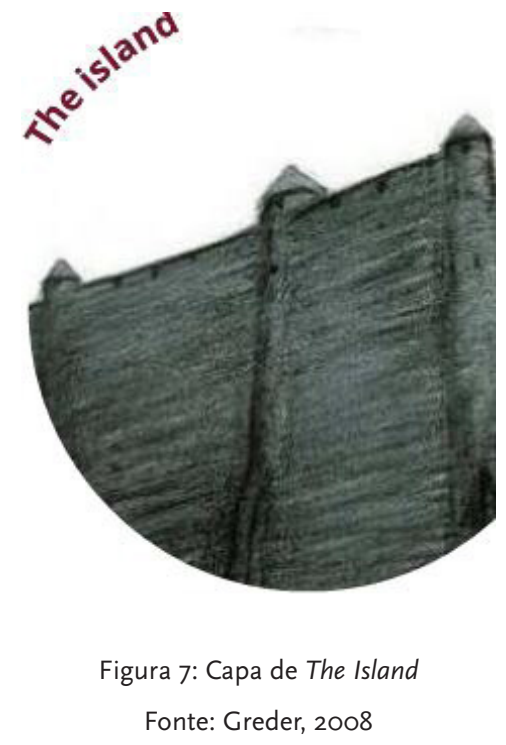

The island, de Armin Greder (2008), é um livro-álbum sombrio sobre uma comunidade que se recusa aceitar que um náufrago se estabeleça no seu território, uma ilha-fortaleza, e que acaba por o escorraçar de volta ao mar, condenando-o à morte. A narrativa gráfica expõe importantes princípios morais e valores relativos: convida ao debate sobre o que significa justiça social, aceitação do outro, ser acolhedor. Fala de exclusão, barreiras linguísticas e culturais, xenofobia, falta de conhecimento sobre o outro, medo e preconceito. Expõe também emoções de quem procura proteção: tristeza, solidão, ausência de relação, coragem e desespero.

Como estratégias de exploração, sugerimos: expor as capas dos quatro livros-álbum e perguntar: És a personagem principal de uma destas histórias. Qual gostarias de ser? Porquê? Como te sentirias? Como sabes que essas seriam as tuas emoções?

Ou: a partir de diversas imagens dos livros-álbum: como tratarias um refugiado ou um imigrante? Já viajaste? Era tudo igual? O que era diferente? $\mathrm{O}$ que é que sentiste? Quais achas que seriam as novas experiências de um refugiado ou imigrante no teu país? (mostrar quatro imagens dos livros-álbum como modelos - escola, medo, abraço e tarefas quotidianas, como lavar o chão com esfregona, aspirar, cozinhar e comer).

Ou: nova sequência de imagens de reunião dos diversos livros-álbum: o que achas que significa ter direito a um lar? Como te sentes em casa? O que fazes? Quem te acompanha? Como receberias Azzi na tua casa? Como a farias sentir-se à vontade?

Ou: sequência de imagens dos livros-álbum: uma fortaleza, uma rapariga a ler, rapazes a jogar à bola, uma escola onde as crianças estão a aprender. 
$\mathrm{O}$ que torna um lugar seguro? Por que temos medo das outras pessoas? $\mathrm{O}$ medo é genuíno ou construído? Porque receamos o que não conhecemos? O que é coragem? Como rescreverias estas histórias?

\section{Conclusões}

Refletir sobre as condições sociais atuais com crianças requer uma coleção adequada de livros-álbum no sentido de um conjunto de sentidos e imaginação (Lewis, 2002) que podem ser explorados pelos leitores de diversos modos e cujos sentidos não são estáveis, mas sempre articulados a partir da experiência do leitor. Adicionalmente, os livros-álbum devem convidar à disputa de sentido para auxiliar os leitores a construir, negociar e transformar mundovisões (Botelho \& Rudman, 2009).

É expectável que existam disjunções entre as interpretações aqui apresentadas e as respostas de crianças e jovens aos livros-álbum, face aos seus interesses, circunstâncias e até ideias do que significa ler.

Mostrámos o que é possível fazer de um ponto de vista pedagógico: compilar uma coleção de livros-álbum, que seja ilustrativa para abordar um determinado tópico e que apresente capacidades reprodutivas e de distribuição de sentidos. Em seguida, propor um conjunto de estratégias de como podem ser mediados junto dos leitores, de forma a criar oportunidades de eles conhecerem o mundo e desenvolverem as competências necessárias para nele atuar.

Dada a configuração do mundo social atual, realçámos o uso de livros-álbum por promoverem a literacia visual; contudo, não se propuseram livros-álbum sobre grupos específicos de pessoas ou sobre uma cultura específica; mesmo quando se aborda o tópico dos refugiados procurou-se situá-lo no âmbito de migrações com diversas motivações e a partir de tradições literárias de expressão cultural distintas e utilizar livros-álbum em línguas diferentes como forma de evitar essencialismos culturais e valorizar a multiculturalidade e o plurilinguismo.

\section{FinANCIAMENTO E AGRADECIMENTOS}

Esta publicação recorreu a materiais desenvolvidos no âmbito do projeto IDPBC "Identity and Diversity in Picture Book Collections", no qual a autora participou, e que recebeu financiamento do programa Erasmus+, com o contrato n. 2015-1-LTO1-KA201-013492.

Aviso: Este texto reflete apenas as opiniões da autora, e a Agência Executiva de Educação, Audiovisual e Cultura e a Comissão Europeia não podem ser responsabilizadas por qualquer uso que possa ser feito das informações nele contidas.

\section{REFERÊNCIAS}

Adichie, C. N. (2009). The danger of a single story. [Vídeo]. Retirado de https://www.ted.com/talks/ chimamanda_adichie_the_danger_of_a_single_story?language 
Amnistia Internacional (2015). We are all born free. Londres: Frances Lincoln Children's Books.

Baghban, M. (2007). Immigration in childhood: using picture books to cope. Social Studies, 98(2), 71-76. https://doi.org/10.3200/TSSS.98.2.71-76

Baker, P. \& Mohieldeen, Y. (2000). The languages of London's schoolchildren. In P. Baker \& J. Eversley (Eds.), Multilingual capital (pp. 5-60). Londres: Battlebridge.

Botelho, M. \& Rudman, M. K. (Eds.) (2010). Critical Multicultural analysis of children's literature. Mirrors, windows, and doors. Nova lorque: Routledge.

Breidbach, S. (2013). Plurilingualism, democratic citizenship in Europe and the role of English. Estrasburgo: Council of Europe.

Bruner, J. (1986). Actual minds, possible worlds. Cambridge, M. A.: Harvard University Press.

Byram, M. (1997). Teaching and Assessing intercultural communicative competence. Clevedon: Multilingual Matters.

Cotton, P. \& Daly, D. (2014). Visualising cultures: the "European picture book collection" moves "down under". Children's Literature in Education, 46(1), 88-106. http://doi.org/10.1007/s10583-014-9228-9

de la Pena, M. \& Robinson, C. (2015). Last stop on market street. Nova lorque: G.P. Putnam's Sons Books for Young Readers.

Djikic, M., Oatley, K. \& Moldoveanu, M. C. (2013). Reading other minds. Effects of literature on empathy. Scientific Study of Literature, 3(1), 28-47. https://doi.org/10.1075/ssol.3.1.06dji

Dubois, C. K. (2012). Akim court. Paris: L'école des loisirs.

Garland, S. (2012). Azzi in Between. Londres: Frances Lincoln Children's Books.

Graham, J. (1990). Pictures on the page. Sheffield: National Association for Teaching English.

Greder, A. (2008). The island. Sydney: Allen \& Unwin.

Gregersen-Hermans, J. (2015). The impact of exposure to diversity in the international university environment and the development of intercultural competence in students. In A. Curaj, L. Matei, R. Pricopie, J. Salmi \& P. Scott (Eds.), The European higher education area (pp 73-92). Cham: Springer. https://doi. org/10.1007/978-3-319-20877-0_6

Harris, R. (2003). Language and new ethnicities: multilingual youth and diaspora. London: King's College Working Papers in Urban Language \& Literacies.

Israel, R. C. (2012). What does it mean to be a global citizen? Kosmos, 79. Retirado de http://www. kosmosjournal.org/wp-content/article-pdfs/what-does-it-mean-to-be-a-global-citizen.pdf

Kobald, I. \& Blackwood, F. (2014). My two blankets. Austrália: Little Haire Book.

Lewis, J. (2002). From culturalism to transculturalism. lowa Journal of Cultural Studies, 1, 14-32. https://doi. org/10.17077/2168-569X.1003

Mateos, M. C. (2010). Migrando. Lisboa: Orfeu Negro.

Meek, M. (1991). On being literate. Londres: Random House Children's Publishers. 
Mendenhall, M. E., Stevens, M. J., Bird, A., Oddon, G. R. \& Osland, J. S. (2001). Intercultural effectiveness scale. Technical report. Chesterfield: The Kozai group, Inc.

Ministério da Educação. (s.d.). Organização curricular e programas. Estudo do Meio (pp. 100-114). Lisboa: Ministério da Educação. Retirado de https://www.dge.mec.pt/sites/default/files/Basico/Metas/Estudo_ Meio/eb_em_programa_ic.pdf

Oxley, L. \& Morris, P. (2013). Global citizenship: a typology for distinguishing its multiple conceptions. British Journal of Educational Studies, 61(3), 301-325. https://doi.org/10.1080/00071005.2013.79839

Parekh, B. (2013). Cosmopolitanism and global citizenship. Review of International Studies, 29, 3-17. https:// doi.org/10.1017/So260210503000019

Portalla, T. \& Chen, G.-M. (2010). The development and validation of the intercultural effectiveness scale. Intercultural Communication Studies, XIX (3), 21-37. Retirado de https://web.uri.edu/iaics/ files/O2TamraPortallaGuo-MingChen.pdf

Rampton, B. (2005). Crossing: language Q ethnicity among adolescents. Manchester: St Jerome Press.

Roche, M. (2010). Critical thinking and book talk: using picture books to promote discussion and critical thinking in the classroom. Reading news (Conference edition). Dublin: Reading Association of Ireland.

Roche, M. (2015). Developing children's critical thinking through picture books. A guide for primary and early years' students and teachers. Oxon: Routledge.

Sen, A. (2006). Identity and violence: the illusion of destiny. Londres: W.B. Norton and Co. Ltd.

Speer, N. K., Reynolds, J. R. \& Zacks, J. M. (2009). Reading stories activates neural representations of visual and motor experience. Psychological Science, 20(8), 989-999. https://doi. org/10.1111/j.1467-9280.2009.02397.x

Unesco. (s.d.). Media and information literacy. [portal web]. Retirado de http://www.unesco.org/new/en/ communication-and-information/media-development/media-literacy/mil-as-composite-concept

Vertovec, S. (2006). The emergence of super-diversity in Britain. Compass, Working Paper No 25. Oxford: University of Oxford.

\section{NOTA BIOGRÁFICA}

Margarida Morgado é Professora Coordenadora de Estudos Culturais Ingleses na Escola Superior de Educação do Instituto Politécnico de Castelo Branco, Portugal, onde ensina e desenvolve investigação sobre o ensino do Inglês, Educação, Comunicação e Mediação intercultural, Leitura e literatura infanto-juvenil.

ORCID: https://orcid.org/o0oo-0002-3651-3030

Email: marg.morgado@ipcb.pt

Morada: Escola Superior de Educação, Rua Professor Doutor Faria de Vasconcelos 6000-266 Castelo Branco

\section{* Submetido: $20 / 07 / 2018$}

* Aceite: $21 / 09 / 2018$ 